\title{
A survey study on the associations between misperceptions on substance use by peers and health and academic outcomes in university students in North-West Europe
}

Cécile R. Boot ${ }^{1, *}$, Marie Dahlin ${ }^{2}$, Tomi Lintonen ${ }^{3}$, Christiane Stock $^{4}$, Guido Van Hal ${ }^{5}$, Susan Rasmussen ${ }^{6}$ and John McAlaney ${ }^{7}$

${ }^{1}$ Department of Research, Development and Prevention, Student Health Services, University of Amsterdam, Amsterdam, The Netherlands

${ }^{2}$ Department of Clinical Neuroscience, Centre for Psychiatric Research and Education, Karolinksa Institutet, Stockholm, Sweden

${ }^{3}$ Finnish Foundation for Alcohol Studies, Helsinki, Finland and University of Tampere, School of Health Sciences, Tampere, Finland

${ }^{4}$ Unit for Health Promotion Research, University of Southern Denmark, Esbjerg, Denmark

${ }^{5}$ Department of Epidemiology and Social Medicine, University Scientific Institute for Drug Problems, University of Antwerp, Campus Drie Eiken, Wilrijk, Belgium

${ }^{6}$ School of Psychological Sciences and Health, University of Strathclyde, Glasgow, Scotland, UK

${ }^{7}$ Psychology General Office, Bradford University, Richmond Building, Bradford, West Yorkshire, UK

\footnotetext{
Abstract

Introduction: The basis of Social Norms Theory is that behavior is influenced by the perception of peer behavior. This implies that an overestimation (misperception) of substance use by peers would lead to an increase in personal substance use. It is hypothesized that the misperception of substance use by peers is negatively associated with health and academic performance, and that this association can be explained by an increase in personal substance use. The aim of this study is to investigate the associations of misperception of consumption of tobacco, alcohol, and recreational drugs with health and academic performance, and to test whether or not this association could be explained by substance use in a sample of university students.

Methods: Data of 6403 university students in five European countries were gathered through a questionnaire about substance use by themselves and by peers, physical and mental

*Corresponding author: Cécile R. Boot, PhD, Department of Public and Occupational Health, EMGO Institute for Health and Care Research, VU University Medical Center, Room BS7-C573, PO Box 7057, 1007 MB Amsterdam, The Netherlands E-mail: crl.boot@vumc.nl Received August 20, 2011; accepted October 25, 2011
}

health, and academic functioning. Misperception is defined as an overestimation of the estimated prevalence of substance use among students. Multivariate models are built with misperception regarding tobacco, alcohol and recreational drugs, and personal use of substances as independent variables, and health and academic performance as dependent variables.

Results: Misperception is significantly associated with health and academic functioning. This association could not be explained by personal substance use.

Conclusions: This study subscribes to an earlier work on the importance of social norms, which indicates a negative influence of misperceptions on health and academic outcomes.

Keywords: public health; social behavior; students; substance use.

\section{Introduction}

Smoking tobacco, drinking alcohol, and using recreational drugs is prevalent among university students $(1,2)$. Substance use has been shown to be associated with diminished emotional wellbeing and a suboptimal health status (3). Apart from the health effects of tobacco, alcohol or drugs, using these substances may also affect functioning at school or at university (4-6).

In a review, Berkowitz states that peer influences have a greater impact on individual behavior than biological, personality, familial, religious, cultural, and other influences (7). This is the basis of Social Norms Theory, which states that behavior is influenced by the perception of peer behavior. An overestimation of alcohol consumption of peers may have unfavorable consequences for personal alcohol consumption by students (7). In the past decades, research in the US has shown that students tend to overestimate the consumption of alcohol by their student peers (8-10). Recently, European researchers have started to investigate this topic as well, and their findings point in a similar direction, with a high proportion of students overestimating alcohol consumption by their peers $(11,12)$.

According to Social Norms Theory, students are expected to change their behavior in accordance with the social norms. This would imply that an overestimation of alcohol consumption by peers would lead to an increase in personal alcohol consumption. It is hypothesized that misperception regarding substance use by peers would be associated with worse health and academic outcomes, and these outcomes can be explained by an increase in personal substance consumption. 
The aim of this study is to test two hypotheses: 1) misperception on substance use by peers is a determinant of reduced health and academic outcomes in university students in Western Europe, and 2) the negative association between misperception on substance use and health and academic outcomes can be explained by an increase in one's personal use of tobacco, alcohol, and recreational drugs.

\section{Methods}

University students in the Netherlands, Belgium, Denmark, Finland, and Sweden were invited to complete an internet-based questionnaire about their consumption of alcohol and self-rated health. Given that this was an anonymous questionnaire on a voluntary basis, this study was exempt from the Medical Ethical Review.

\section{Populations}

The study populations consisted of samples from university students in five European countries, including the University of Amsterdam in the Netherlands $(n=4836)$, Antwerp University in Belgium $(n=27,210)$, University of Southern Denmark $(n=18,254)$, Police College of Finland $(n=548)$, and the Karolinska Institute in Sweden $(n=5189)$. From hereon, we shall refer to these five populations by referring to the countries.

\section{Study protocol}

The questionnaire was Internet based, implying that data were collected from students through a www-based survey link, which was disseminated via email. This technique has been argued to be an effective data collection approach when researching computerliterate university students (13). In addition, data were collected at the University of Antwerp (Belgium) via a student health website associated with a separate health promotion project. Each survey was translated by one of the co-authors into the appropriate language for each site. Reminder emails were sent out approximately one week after the initial invitation, however in each instance, the majority of responses were returned within $48 \mathrm{~h}$ of the first email

\section{Questionnaire content}

In keeping with the existing social norms literature, the questionnaire items used were simple ones that focused on key aspects of the target behaviors with categorical or ordinal variables, and which could also be easily translated between sites (11).

\section{General information}

Sex, age, type of study (business, science, medicine/health care, social science, arts/humanities, law, education, and others), and university (Belgium, the Netherlands, Denmark, Finland, and Sweden), were investigated by multiple choice questions retrieved from a questionnaire previously developed for use in student health research (14).

\section{Academic outcome}

Academic outcome was operationalized as a delay in the study program and was investigated by self-reports, using a single item: "Are you experiencing a delay in your study program at this moment"? with answering options that included "yes" and "no" (14).

\section{Health}

Students' perception of their health was investigated using a single item SRH-5: "How do you evaluate your health in general"? with a Likert scale between 1 (excellent) and 5 (bad) (15). This measure was dichotomized into an outcome variable "suboptimal health", which was coded 0 for response alternatives 1 and 2 and 1 for answering options $3-5$, corresponding to a previous study on the health of medical students (16).

\section{Substance use}

Substance use was investigated using questions regarding selfreported use of tobacco, alcohol, and recreational drugs. For tobacco and recreational drugs, these questions related to whether or not the students used either. For alcohol, students were asked how often they drank alcohol in the past month and how often they had become drunk in the past month, both with answering options from 1 (not at all) to 8 (every day). Answering options are listed in Table 2.

\section{Social norms}

Social norms regarding substance use were investigated by asking the participants about their estimations of the respective percentages (response alternatives in 10\% increments) of students at their own university that smoked tobacco, drank alcohol, or used recreational drugs. In addition, they were asked to estimate the frequency of alcohol consumption of their peer students in the past month and the frequency of drunkenness by these peers in the past month (11).

\section{Definition of misperception}

According to the Social Norms Theory (7), overestimation is related to actual behavior. Thus, we only defined misperception as overestimation; underestimation - known to be very uncommon - was considered in the group without misperception. Therefore, in this study we defined misperception as a higher estimated prevalence of consumption of substances among students (the social norms) per university than the actual reported consumption of substances of the students who completed the questionnaire. The social norms were determined per university, because country differences are known to exist for prevalence of substance use $(17,18)$.

For smoking tobacco and consumption of recreational drugs, misperception was based on the percentage of users amongst the respondents. For example, $23 \%$ of respondents at the University of Amsterdam reported smoking tobacco. All students who chose the answering category that $30 \%-39 \%$ or more of their peer students smoked tobacco were classified as having misperception regarding smoking tobacco by peer students. The social norms are listed in Table 3.

For frequency of alcohol consumption and frequency of drunkenness, the median category of the actual use of the students was used to define the "correct" prevalence. For example, the answering option "drinking alcohol twice a week" was the median category chosen by university students in Amsterdam. This implied that participants who answered that students at their university drank alcohol three to four days per week or more often were classified as having misperception regarding frequency of alcohol consumption. Young people are highly capable of reporting their alcohol consumption and drunkenness in a valid and reliable way (19). 


\section{Analyses}

Logistic regression analyses (Enter method) were performed to calculate multivariate models for self-rated health and academic outcomes (delay in the study program) as dependent variables. A similar approach was followed for both dependent variables. First, each misperception variable (frequency of alcohol consumption, frequency of drunkenness, and smoking tobacco and consumption of recreational drugs) was included as an independent variable in a model, together with the confounders (age, sex, and university). Odds ratios were calculated for the misperception variable. Next, all misperception models were corrected for personal consumption of tobacco, frequency of alcohol consumption, frequency of drunkenness, and consumption of recreational drugs by adding these variables to the models. A value of $\mathrm{p}<0.05$ was considered statistically significant. SPSS 15.0 software was used for all analyses.

\section{Results}

A total of 6403 students completed the questionnaire. Except for those enrolled in Finland, most students were females. In Belgium, Denmark and Sweden, most students were younger than 20 years, whereas those in the Netherlands and Finland were older (Table 1). The response rate varied per university. Response rate is $13 \%$ in Denmark, $26 \%$ in the Netherlands, $33 \%$ in Sweden, and $66 \%$ in Finland. In Belgium, 659 surveys were completed, comprising $2 \%$ of the total student population. However, since data were collected from a website rather than through an email survey, it was not possible to calculate a response rate comparable to the other sites.

Students from Sweden (who were studying at the health faculty) and Finland reported the lowest and highest general self-rated health, respectively. The percentage of students reporting a delay in their study program was highest in Netherlands (33\%) and lowest in Finland (2\%).

More than $85 \%$ of the students drank alcohol, and there were no major differences between universities (Table 2). Among all respondents, 56\% consumed alcohol once a week or more; the highest prevalence was found in the Netherlands (66\%) and Belgium (63\%). Then, 66\% of all respondents reported that they were drunk at least once a month, the highest prevalence of which was reported in Denmark (72\%) and Finland $(68 \%)$. Among all the participants, $18 \%$ smoked tobacco, with the lowest and highest prevalence in Sweden $(9 \%)$ and Belgium (27\%), respectively. Moreover, $9 \%$ of the participants used recreational drugs, although this high percentage was mainly due to the number of recreational drug users in the Netherlands (19\%) and Belgium (17\%).

\section{Misperception}

A total of $52 \%$ of all participants overestimated the frequency of alcohol consumption by their student peers (Table 3). Students from Denmark and Belgium showed the highest percentage of misperception regarding frequency of alcohol consumption (73\% and $71 \%$, respectively). The frequency of drunkenness was overestimated in more than $79 \%$ of the cases, with the highest percentages in the Netherlands and Belgium
(78\%) and Denmark (85\%). Misperception regarding smoking tobacco occurred in $82 \%$ of the participants, without any major differences between universities. Then, $51 \%$ of all respondents overestimated the use of recreational drugs by their peers. Large differences exist between countries; the prevalence of misperception regarding consumption of recreational drugs ranged from $5 \%$ in Finland to $65 \%$ in the Netherlands. The degree of underestimation was lower than $5 \%$.

\section{Multivariate models for self-rated health}

Misperception on tobacco smoking, frequency of drunkenness, and consumption of recreational drugs was associated with a lower self-rated health (Table 4). After correcting for personal consumption of tobacco, alcohol (including frequency of drunkenness) and recreational drugs, these associations remained significant. Misperception regarding the frequency of alcohol consumption was not significantly associated with self-rated health.

\section{Multivariate models for academic functioning}

Misperception on frequency of drunkenness and consumption of recreational drugs were both associated with worse academic functioning (more delay in the study program) (Table 4). The direction of the association was different between the two misperception variables; specifically, misperception regarding consumption of recreational drugs was associated with worse academic functioning, while misperception regarding the frequency of drunkenness was associated with better academic functioning. After correcting the models for personal consumption of tobacco, alcohol (including frequency of drunkenness) and recreational drugs, these associations remained significant.

\section{Discussion}

This was the first study to investigate associations between misperceptions regarding substance consumption and health and academic outcomes among university students in different cities in Europe. In addition, we aimed to gain insights into the contribution of personal substance consumption to the association between health and academic outcomes on the one hand, and misperception on the other hand. Our main finding revealed that misperception regarding alcohol, tobacco, and recreational drugs was significantly associated with unfavorable health and academic outcomes. However, this association could not be explained by personal consumption of tobacco, alcohol, and recreational drugs.

\section{Misperception regarding substance use and health and academic outcomes}

The high proportion of students with misperception regarding substance use is in line with a study in the US, in which the student participants overestimated alcohol use, drug use, and sexual behavior among peers $(10,20)$. According to Social 
Table 1 Descriptive data of the populations per university, referred to as the country, expressed as column percentages.

\begin{tabular}{|c|c|c|c|c|c|c|}
\hline $\begin{array}{l}\text { University in } \\
\mathrm{n}\end{array}$ & $\begin{array}{l}\text { NL } \\
1265 \\
\%\end{array}$ & $\begin{array}{l}\mathrm{BG} \\
659 \\
\%\end{array}$ & $\begin{array}{l}\text { DM } \\
2420 \\
\%\end{array}$ & $\begin{array}{l}\text { SW } \\
1696 \\
\%\end{array}$ & $\begin{array}{l}\text { FL } \\
364 \\
\%\end{array}$ & $\begin{array}{l}\text { Total } \\
6403 \\
\%\end{array}$ \\
\hline \multicolumn{7}{|l|}{ Gender } \\
\hline Male & 34.4 & 38.5 & 43.3 & 22.8 & 70.3 & 37.2 \\
\hline Female & 65.6 & 61.5 & 56.7 & 77.2 & 29.7 & 62.8 \\
\hline \multicolumn{7}{|l|}{ Age } \\
\hline$\leq 20$ years & 25.6 & 70.5 & 54.4 & 44.7 & 1.4 & 25.6 \\
\hline $21-24$ years & 51.1 & 26.4 & 39.7 & 40.4 & 45.9 & 51.1 \\
\hline$\geq 25$ years & 23.2 & 3.0 & 5.8 & 14.9 & 52.7 & 23.2 \\
\hline \multicolumn{7}{|l|}{ Course } \\
\hline Business & 0.6 & 15.3 & 14.8 & & & 0.6 \\
\hline Science & 10.0 & 5.5 & 22.7 & & & 10.0 \\
\hline Medicine/health & 26.6 & 15.4 & 20.8 & 100.0 & & 26.6 \\
\hline Social science & 29.0 & 14.7 & 14.6 & & & 29.0 \\
\hline Arts/humanities & 31.2 & 5.8 & 19.9 & & & 31.2 \\
\hline Law & 0.9 & 2.1 & 3.0 & & & 0.9 \\
\hline Education & & 9.6 & 0.7 & & & \\
\hline Policing & & & & & 100.0 & \\
\hline Other & 1.7 & 31.5 & 3.5 & & & 1.7 \\
\hline \multicolumn{7}{|l|}{ Health } \\
\hline $\begin{array}{l}\text { Excellent }(1)- \\
\text { poor }(5)^{\mathrm{a}}\end{array}$ & $2.2(0.8)$ & $2.2(0.8)$ & $2.3(0.9)$ & $2.6(0.9)$ & $2.0(0.8)$ & $2.3(0.9)$ \\
\hline $\begin{array}{l}\text { Low academic } \\
\text { functioning, } \%\end{array}$ & 33.3 & 21.2 & 23.2 & 14.2 & 1.9 & 21.4 \\
\hline
\end{tabular}

aData presented as mean (standard deviation). NL, The Netherlands; BG, Belgium; DM, Denmark; SW, Sweden; FL, Finland.

Norms Theory, misperception regarding substance use by peers is associated with increased personal consumption of substances. This was shown in studies in the US, where a positive relationship with actual behavior was observed, although the effect sizes were small $(9,11,20)$. One study in France investigated correlates of smoking behavior in students and found that smoking behavior was associated with a high selfrated prevalence of smoking among friends (21).

Table 2 Descriptive results (column percentages) on substance use and misperception.

\begin{tabular}{|c|c|c|c|c|c|c|c|}
\hline Substance use & $\begin{array}{l}\mathrm{n}=6403 \\
\mathrm{n}\end{array}$ & $\begin{array}{l}\text { NL } \\
1265\end{array}$ & $\begin{array}{l}\text { BG } \\
659\end{array}$ & $\begin{array}{l}\text { DM } \\
2420\end{array}$ & $\begin{array}{l}\text { SW } \\
1696\end{array}$ & $\begin{array}{l}\text { FL } \\
364\end{array}$ & $\begin{array}{l}\text { Total } \\
6403\end{array}$ \\
\hline \multirow{8}{*}{$\begin{array}{l}\text { Frequency of alcohol } \\
\text { consumption in the past } \\
30 \text { days }\end{array}$} & Not at all & 9.8 & 9.4 & 8.8 & 15.1 & 10.4 & 10.8 \\
\hline & Once a month & 8.3 & 9.0 & 13.4 & 0 & 24.5 & 9.0 \\
\hline & $2-3 /$ month & 15.4 & 18.8 & 32.2 & 18.9 & 41.5 & 24.5 \\
\hline & Once a week & 16.0 & 15.5 & 20.5 & 29.2 & 14.6 & 21.0 \\
\hline & 2/week & 23.7 & 23.6 & 15.3 & 18.9 & 5.8 & 18.2 \\
\hline & 3-4/week & 20.9 & 18.5 & 7.3 & 13.9 & 2.7 & 12.6 \\
\hline & 5-6 days/week & 4.9 & 4.7 & 2.0 & 3.9 & 0.3 & 3.3 \\
\hline & Every day & 0.9 & 0.5 & 0.6 & 0.2 & 0.3 & 0.5 \\
\hline \multirow{8}{*}{$\begin{array}{l}\text { Frequency of drunkenness } \\
\text { in the last month }\end{array}$} & Not al all & 41.2 & 35.1 & 27.6 & 37.5 & 32.2 & 34.0 \\
\hline & Once a month & 26.4 & 25.9 & 30.0 & 33.3 & 41.6 & 30.4 \\
\hline & $2-3 /$ month & 15.5 & 15.7 & 25.4 & 20.2 & 20.7 & 20.8 \\
\hline & Once a week & 9.7 & 9.6 & 11.0 & 6.6 & 3.9 & 9.0 \\
\hline & 2/week & 5.1 & 8.7 & 5.0 & 2.0 & 0.6 & 4.3 \\
\hline & 3-4 days/week & 1.3 & 4.0 & 0.6 & 0.4 & 0.6 & 1.0 \\
\hline & 5-6 days/week & 0.6 & 0.6 & 0.2 & 0 & 0.3 & 0.3 \\
\hline & Every day & 0.3 & 0.5 & 0.2 & 0 & 0.3 & 0.2 \\
\hline Smoking tobacco & & 23.0 & 26.9 & 17.8 & 8.9 & 19.2 & 17.5 \\
\hline Using recreational drugs & & 18.8 & 16.6 & 6.9 & 4.4 & 0.5 & 9.2 \\
\hline
\end{tabular}

NL, The Netherlands; BG, Belgium; DM, Denmark; SW, Sweden; FL, Finland. 
Table 3 Social norms and misperception figures in all countries.

\begin{tabular}{|c|c|c|c|c|c|c|}
\hline Social norms and misperception & NL & BG & $\mathrm{DM}$ & SW & FL & Total \\
\hline Social norm frequency of alcohol & 2/week & 2/week & $2-3 /$ month & 1/week & $2-3 /$ month & $2-3 /$ month \\
\hline Misperception on frequency of alcohol ${ }^{\mathrm{a}}$ & 37.4 & 71.2 & 73.3 & 24.8 & 53.0 & 52.0 \\
\hline Social norm frequency of drunkenness & Never & Never & Once a month & Never & Once a month & Never \\
\hline Misperception on frequency of drunkenness ${ }^{\mathrm{a}}$ & 78.0 & 77.8 & 85.2 & 71.6 & 75.5 & 78.9 \\
\hline Social norm smoking tobacco & 23.0 & 26.9 & 17.8 & 8.9 & 19.2 & 17.5 \\
\hline Misperception on tobacco smoking ${ }^{\mathrm{a}}$ & 79.4 & 88.1 & 81.5 & 82.8 & 83.8 & 82.2 \\
\hline Social norm recreational drug use & 18.8 & 16.6 & 6.9 & 4.4 & 0.5 & 9.2 \\
\hline Misperception on recreational drug use $\mathrm{a}^{\mathrm{a}}$ & 65.2 & 61.9 & 60.9 & 32.0 & 5.2 & 51.0 \\
\hline
\end{tabular}

aPercentage of students with estimates higher than the norm. NL, The Netherlands; BG, Belgium; DM, Denmark; SW, Sweden; FL, Finland.

An increase of substance use, resulting from misperception regarding substance use by peers affects health and academic outcomes (3-6). However, the present results showed that although misperception was associated with suboptimal self-rated health, this could not be explained by personal substance use. Since this is a cross sectional study, cause and consequence cannot be distinguished; thus, it remains unknown whether students who overestimate the frequency of alcohol consumption by peer students would experience suboptimal self-rated health or whether students with a suboptimal self-rated health are more likely to overestimate substance use by peer students. This cause and consequence issue was addressed previously by Neighbors and colleagues, who suggested the influence of norms on behavior was larger than the influence of behavior on norms (22).

Misperception regarding frequency of alcohol consumption was not associated with suboptimal self-rated health. This may be explained by the fact that different from smoking tobacco and using recreational drugs, drinking alcohol does not have a negative effect on health when consumption is limited to small amounts (23). Unfortunately, we only collected information about the frequency of drunkenness and not the quantity of alcohol students were drinking. It can be assumed that students only drank small amounts on a frequent basis, which may explain the lack of association with health or academic outcomes. Surprisingly, misperception regarding frequency of drunkenness was associated with better academic functioning. However, only a small proportion of students $(7.7 \%) \mathrm{did}$ not have misperception regarding frequency of drunkenness, leading to empty cells in the multivariate models.

When considering academic functioning, only misperception regarding drunkenness and consumption of recreational drugs were significantly associated with academic functioning. This may be explained by the fact that being drunk and using recreational drugs can be expected to have more direct effects on studying at university, such as hangovers or fatigue after using XTC, rather than the health effects of smoking, that need a longer time to develop (e.g., lung disorders).

The results of this study showed that the associations between reduced health and academic performance and misperception cannot be explained by an increased personal use of substances by students, as would be expected from Social Norms Theory (7). Given that this is a cross-sectional study, cause and consequence cannot be distinguished, and as such, the following hypotheses can be formulated: 1) misperception regarding substance use by peers effects health and academic performance independent of personal consumption of substances, and 2) students with low health and worse academic performance are more likely to have misperception regarding substance use by peers. Future research with a longitudinal design is needed to confirm or reject any of these hypotheses.

Table 4 Models for misperception as a determinant of self-rated health and academic functioning delay, separate analyses for tobacco, frequency of alcohol consumption, frequency of drunkenness and recreational drugs, separate for self-rated health and academic functioning.

\begin{tabular}{|c|c|c|c|c|c|c|c|}
\hline \multirow{3}{*}{$\frac{\text { Dependent variable }}{\text { Misperception regarding }}$} & & \multicolumn{3}{|c|}{ Lower self-rated health } & \multicolumn{3}{|c|}{ Worse academic functioning } \\
\hline & & \multirow[t]{2}{*}{ OR } & \multicolumn{2}{|c|}{$95 \% \mathrm{CI}$} & \multirow[t]{2}{*}{ OR } & \multicolumn{2}{|c|}{$95 \% \mathrm{CI}$} \\
\hline & & & Lower & Upper & & Lower & Upper \\
\hline \multirow[t]{2}{*}{ Tobacco smoking } & Crude & 1.19 & 1.04 & 1.37 & 1.03 & 0.88 & 1.21 \\
\hline & Adjusted $^{\mathrm{a}}$ & 1.19 & 1.03 & 1.36 & 1.02 & 0.87 & 1.20 \\
\hline \multirow{2}{*}{ Frequency of alcohol consumption } & Crude & 0.95 & 0.85 & 1.05 & 1.10 & 0.97 & 1.24 \\
\hline & Adjusted $^{\mathrm{a}}$ & 0.95 & 0.85 & 1.05 & 1.13 & 0.99 & 1.28 \\
\hline \multirow[t]{2}{*}{ Frequency of drunkenness } & Crude & 1.25 & 1.03 & 1.52 & 0.74 & 0.59 & 0.93 \\
\hline & Adjusted $^{\mathrm{a}}$ & 1.30 & 1.07 & 1.59 & 0.75 & 0.60 & 0.95 \\
\hline \multirow{2}{*}{ Consumption of recreational drugs } & Crude & 1.19 & 1.07 & 1.34 & 1.32 & 1.16 & 1.50 \\
\hline & Adjusted $^{\mathrm{a}}$ & 1.20 & 1.08 & 1.35 & 1.30 & 1.14 & 1.48 \\
\hline
\end{tabular}

${ }^{a}$ Models adjusted for university, personal consumption of tobacco, alcohol and recreational drugs. Bold values indicate $\mathrm{p}<0.05$. OR, Odds ratio; CI, confidence interval. 


\section{Methodological considerations}

The results of this study should be interpreted with caution due to the fact that the data were collected in different countries, where cultural and legislative differences exist. Nevertheless, these cultural differences can be considered small, since only students from North-Western European countries participated in this study. However, differences between countries, cities, and universities with regards the prevalence of substance consumption are overcome since we determined the social norms and misperception per university. In addition, it should be mentioned that since we included only one university per country, we investigated differences between universities or cities, rather than countries. The data rely on self reports regarding consumption of tobacco, alcohol, and recreational drugs. Previous research, however, has shown that young people are capable of giving valid reports about their consumption of alcohol (19).

The social norms in this study are based on the norm set by the participants. It is likely that students who drink alcohol more often are less likely to complete the questionnaire, although the high percentage of misperception has been presented in other studies as well (9-11). A final remark on the social norms in this study is that misperception has been defined as an overestimation of actual consumption, and not an underestimation. In our study, only a small percentage of respondents underestimated the consumption of substances by their peers. Given that overestimation is a risk factor for increasing personal consumption according to social norms theory, we decided to focus on overestimation only. Finally, the results of this study rely on self-reported data of a selection of student populations of all universities stated above. With the low response rates in some countries, we have to keep in mind that this group of participants may not be a representative sample of all students in those countries. Moreover, since our research aim is not to investigate prevalence, but the associations between variables, we do not expect that selection bias can have a large effect on the results presented here.

\section{Conclusions}

From the results of this study, it can be concluded that for university students in North-Western Europe, their misperception of substance use by their peers is associated with unfavorable health and academic outcomes. Although this is a cross-sectional study, this finding subscribes to the results of earlier work on the importance of social norms. The associations between misperception and health and academic outcomes are independent of an increase in personal consumption of substances through misperception. Future research is needed to gain insights into whether students with worse health and academic performance are more likely to have misperceptions regarding substance use by peers, or whether having misperceptions regarding substance use by peers negatively influences health and academic performance of university students.

\section{Acknowledgments}

The authors would like to acknowledge the assistance of Dr. Katarina Widgren, at the time MSc student at London School of Hygiene and Tropical Medicine in undertaking translation work on the survey that was conducted.

\section{Conflict of interest statement}

Authors' conflict of interest disclosure: The authors stated that there are no conflicts of interest regarding the publication of this article.

Research funding: None declared.

Employment or leadership: None declared.

Honorarium: None declared.

\section{References}

1. O’Malley PM, Johnston LD. Epidemiology of alcohol and other drug use among American college students. J Stud Alcohol 2002;14:23-39.

2. Stock C, Larsen NM. The lifestyles of university students and their interest in campus health promotion. A cross-sectional study. Ugeskr Laeger 2008;170:334-39. (In Danish).

3. Steptoe A, Wardle J. Health behaviour, risk awareness and emotional well-being in students from Eastern Europe and Western Europe. Soc Sci Med 2001;53:1621-30.

4. Lynskey M, Hall W. The effects of adolescent cannabis use on educational attainment: a review. Addiction 2000;95: 1621-30.

5. Fergusson DM, Horwood LJ, Beautrais AL. Cannabis and educational achievement. Addiction 2003;98:1681-92.

6. Bergen HA, Martin G, Roeger L, Allison S. Perceived academic performance and alcohol, tobacco and marijuana use: longitudinal relationships in young community adolescents. Addict Behav 2005;30:1563-73.

7. Berkowitz AD. The social norms approach: theory, research, and annotated bibliography. Trumansburg, NY: Berkowitz, 2004.

8. Perkins HW, Berkowitz AD. Perceiving the community norms of alcohol use among students: some research implications for campus alcohol education programming. Int $\mathrm{J}$ Addict 1986;21:961-76.

9. Perkins HW, Meilman PW, Leichliter JS, Cashin JR, Presley CA. Misperceptions of the norms for the frequency of alcohol and other drug use on college campuses. J Am Coll Health 1999;47:253-8.

10. Perkins HW, Haines MP, Rice R. Misperceiving the college drinking norm and related problems: a nationwide study of exposure to prevention information, perceived norms and student alcohol misuse. J Stud Alcohol 2005;66:470-8.

11. McAlaney J, McMahon J. Normative beliefs, misperceptions, and heavy episodic drinking in a British student sample. J Stud Alcohol Drugs 2007;68:385-92.

12. Bewick BM, Trusler K, Mulhern B, Barkham M, Hill AJ. The feasibility and effectiveness of a web-based personalised feedback and social norms alcohol intervention in UK university students: a randomised control trial. Addict Behav 2008;33: 1192-8.

13. Kypri K, Gallagher SJ, Cashell-Smith ML. An internet-based survey method for college student drinking research. Drug Alcohol Depend 2004;76:45-53. 
14. Boot CR, Donders NC, Vonk P, Meijman FJ. Development of a student health questionnaire: the necessity of a symbiosis of science and practice. Global Health Promot 2009;16:35-44.

15. Eriksson I, Unden AL, Elofsson S. Self-rated health. Comparisons between three different measures. Results from a population study. International J Epidemiol 2001;30:326-3.

16. Dahlin M, Joneborg N, Runeson B. Performance-based selfesteem and burnout in a cross-sectional study of medical students. Med Teach 2007;29:43-8.

17. Hibell B, Andersson B, Ahlström S, Balakireva O, Thoroddur B, Kokkevi A, et al. The 1999 ESPAD report: alcohol and other drug use among students in 30 European countries. Stockholm: ESPAD, 2000.

18. Stock C, Mikolajczyk R, Bloomfield K, Maxwell AE, Ozcebe H, Petkeviciene J, et al. Alcohol consumption and attitudes towards banning alcohol sales on campus among European university students. Public Health 2009;123:122-9.
19. Lintonen T, Rimpela MK. The validity of the concept of "selfperceived drunkenness" in adolescent health surveys. J Subst Use 2001;6:145-50.

20. Martens MP, Page JC, Mowry ES, Damann KM, Taylor KK, Cimini MD. Differences between actual and perceived student norms: an examination of alcohol use, drug use, and sexual behavior. J Am Coll Health 2006;54:295-300.

21. Riou FL, Dautzenberg B, Falissard B, Reynaud M. Are social norms associated with smoking in French university students? A survey report on smoking correlates. Subst Abuse Treat Prev Policy 2009;4:4.

22. Neighbors C, Dillard AJ, Lewis MA, Bergstrom RL, Neil TA. Normative misperceptions and temporal precedence of perceived norms and drinking. J Stud Alcohol 2006;67:290-9.

23. Grønbæk M. The positive and negative health effects of alcohol- and the public health implications. J Intern Med 2009;265:407-20. 